\title{
Photocatalytic Degradation of Azo and Rhodamine Dyes Using Copper (II) Oxide Nanoparticles
}

\author{
Etchu E. Mbu, David Dodoo-Arhin, Seteno K. Ntwampe, Edward Malenga and Elvis Fosso-Kankeu
}

\begin{abstract}
Fresh water pollution by dyes from various industries is raising a lot of concern lately. Despite their well-known toxicity to humans, azo dyes make up over half of the used dye population. Rhodamines are also a well-used class of dyes in industry. This study employed a cost effective, energy efficient, environmentally benign method to degrade Methyl Orange (MeO), Methylene Blue (MB) and Rhodamine B (RhB) dyes. The photocatalyst used was copper (II) oxide (CuO) nano-sized particles synthesised from $\mathrm{CuSO}_{4} \quad .5 \mathrm{H}_{2} \mathrm{O}, \mathbf{C u}\left(\mathrm{NO}_{3}\right)_{2} \quad . \mathrm{HH}_{2} \mathrm{O}$ and $\mathrm{NaOH}$ via a simple solution route with neither a catalyst, template nor a surfactant. The nanoparticles were characterised and used for the photocatalytic degradation of the above dyes in the presence of $\mathrm{H}_{2} \mathrm{O}_{2}$. The $\mathrm{CuO}$ nanoparticles synthesised from both copper precursors were found to degrade all dyes effectively over the same degradation time interval, recording an overall minimum degradation efficiency of $85 \%$ and maximum of $99 \%$.
\end{abstract}

Keywords-Azo dye, $\mathrm{CuO}$, Nanoparticles, Photocatalysis, Rhodamine dye.

\section{INTRODUCTION}

Wastewater pollution is a major problem in most parts of the world today. One of the recalcitrant pollutants in wastewaters are dyes. They are used in a variety of industries, and have been found to be carcinogenic in man. Of over 3000 known organic dyes, half the number belong to the class of Azo dyes[1][2]. Well-known by their characteristic $-\mathrm{N}=\mathrm{N}$ - (azo) group, these compounds are often preferred due to the relative ease with

E. E. Mbu is with the Department of Materials Science and Engineering, University of Ghana, P.O. Box LG 77, Legon-Accra, Ghana and also with the Bioresource Engineering Research Group (BioERG), Faculty of Applied Science, Department of Biotehnology Cape Peninsula University of Technology, P.O. Box 652, Cape Town 8000, South Africa.

D. Dodoo-Arhin is with the Department of Materials Science and Engineering, University of Ghana, P.O. Box LG 77, Legon-Accra, Ghana and is also a visiting research fellow at the Centre RAPSODEE-CNRS UMR 5302, Ecoles des Mines d'Albi-Carmaux, Campus Jarlard-81013 ALBI Cedex 09, France and at the Cambridge Centre for Advanced Photonics and Electronics, Department of Engineering, University of Cambridge. 9 JJ Thomson Avenue, Cambridge CB3 0FA, United Kingdom.

S. K.O. Ntwampe is the founder of Bioresource Engineering Research Group (BioERG), Faculty of Applied Science, Department of Biotehnology Cape Peninsula University of Technology, P.O. Box 652, Cape Town 8000, South Africa.

E. Malenga, E. Fosso-Kankeu are with School of Chemical \& Minerals Engineering, North-West University, Potchefstroom, South Africa. which they can be synthesised, the wide variety of colours which they offer, their relatively good adherence and long lasting aesthetics[1]. However, they have also been found to comprise mutagenic and carcinogenic compounds when incompletely broken down[3], [4]. Another well know class of dyes are the Rhodamines. Mostly used in the paper, pharmaceutical and cosmetic industries, the extent of their toxicity to man is yet to be clearly defined[5]. With these dyes often released into the environment in wastewater, it is essential to find appropriate ways of rendering the wastewater harmless prior to its release into the environment. This will involve the degradation of any dyes found in the wastewater.

In recent years, Transition Metal Oxides (TMOs) have been investigated for use in the degradation of organic pollutants such as these dyes. Photocatalysis has been found to be one of the effective mechanisms involving the use of these transition metals in the degradation of dyes in solution. Its low energy requirements, easy usability with catalysts in all three phases of matter and eco-compatibility have made it stand out for this application[6]-[8]. It is based on the principle of the photoelectric effect whereby when an electron absorbs a photon (packet) of light energy which is at least equal to its work-function (bandgap energy), it is promoted from the valence to the conduction band. This electron then goes into solution and interacts with the bonding electrons within the molecules in the system. This interaction results in the formation of free radical species which are unstable and very reactive, thereby resulting in further breakdown of any organic molecules present in the system[9].

$\mathrm{TiO}_{2}$ nanoparticles are one of the most widely studied TMOs for the dye-degradation process[3], [7], [9]. Other TMOs that have been studied for this application include $\mathrm{SnO}$ [10], [11], $\mathrm{ZnO}$ and $\mathrm{Cu}_{2} \mathrm{O}[12]$ with others like $\mathrm{CuO}$ which are gaining more attention in recent times.

This study compared the efficiency of degradation of azo (Methyl Orange $(\mathrm{MeO})$ and Methylene Blue $(\mathrm{MB})$ ) and rhodamine (Rhodamine $\mathrm{B}(\mathrm{RhB})$ ) dyes using $\mathrm{CuO}$ nanoparticles synthesised from two different precursor salts and precipitated at three different temperatures. Though other studies have worked with $\mathrm{CuO}$, to the best of our knowledge, it is the first time that $\mathrm{CuO}$ nanoparticles arising from this route of synthesis have been tested in photocatalytic applications. The study sought to assess the extent of degradation of each dye using the 
synthesised $\mathrm{CuO}$ nanoparticles. The overall photocatalytic efficiency of the synthesised nanoparticles was accounted for based on some of the properties observed during characterisation.

\section{MAterials AND MethodS}

\section{A. Reagents}

Analytic grade reagents were used during the entire study. They were, hydrated copper nitrate $\left(\mathrm{Cu}\left(\mathrm{NO}_{3}\right)_{2} \cdot 3 \mathrm{H}_{2} \mathrm{O}\right)$ (Sigma-Aldrich Co., Germany), hydrated copper sulphate $\left(\mathrm{CuSO}_{4} .5 \mathrm{H}_{2} \mathrm{O}\right)$ (Breckland Sc. Supplies, UK), sodium hydroxide (NaOH) (Qualikems Fine Cem Pvt Ltd, India), methyl orange (Fizmerk India Chemicals, India), methylene blue (KEM Light Laboratories Pvt Ltd, Mumbai-India), rhodamine B (Paskem Finechemicals Industry, India), $30 \%$ hydrogen peroxide (Merck, Germany) and ethanol (Fisher Scientific, UK). To reduce interference, during this study, the water used was deionised.

\section{B. Synthesis}

Three $\mathrm{CuO}$ samples (N60, S60 and S25) ${ }^{1}$ were precipitated from $0.02 \mathrm{M}$ copper precursor solutions at $60{ }^{\circ} \mathrm{C}$ and $25{ }^{\circ} \mathrm{C}$ using $1.6 \mathrm{~g} / \mathrm{L}$ of $\mathrm{NaOH}$. Equations 1,2 and 3 summarise the synthesis process for all three $\mathrm{CuO}$ samples.

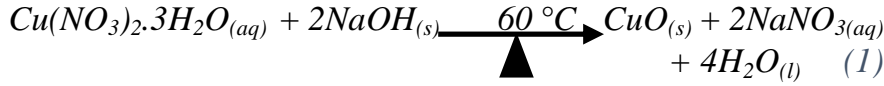

$$
\begin{aligned}
& \mathrm{CuSO}_{4} \cdot 5 \mathrm{H}_{2} \mathrm{O}_{(a q)}+2 \mathrm{NaOH}_{(} \underset{\mathrm{C}}{\stackrel{\circ}{\longrightarrow} \mathrm{C}} \mathrm{CuO}(s)+\mathrm{Na}_{2} \mathrm{SO}_{4(a q)}+
\end{aligned}
$$

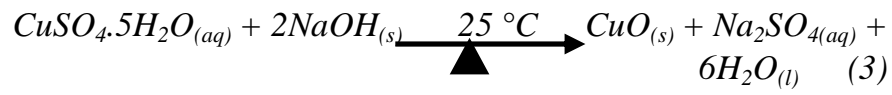

After synthesis, the precipitate was centrifuged, washed with 1:1 ethanol and deionised water. The precipitate was dried in an oven at $70^{\circ} \mathrm{C}$, after which a black $\mathrm{CuO}$ powder was obtained.

\section{Characterisation}

X-Ray Diffraction (XRD) (X'Pert PRO X-Ray Diffractometer (PanAnalytical, the Netherlands) operating with $\mathrm{Cu} \mathrm{K}-\alpha$ radiation (wavelength of $1.544 \AA$ ) at $45 \mathrm{kV}$ and $40 \mathrm{~mA}$ with a $20^{\circ}$ to $70^{\circ} 2 \theta$ range, a $0.2^{\circ}$ step width scanning $1.2 \mathrm{deg} / \mathrm{min}$ on a $2 \mathrm{~g}$ sample) studies were employed to study crystal properties. UV-Vis spectrophotometer( (Thermo Fisher Scientific, China) operating within a scanning range of 200 to $900 \mathrm{~nm}$ with a $5 \mathrm{~nm}$ scan step on a $3 \mathrm{~mL}$ sample) for absorbance. A Scanning Electron Microscope (SEM) - TESCAN with EDX analysis

\footnotetext{
${ }^{1}$ The letter $\mathrm{N}$ and $\mathrm{S}$ denote the precursor salt (nitrate or sulphate) from which the nanoparticles were synthesised while the numbers 60 and 25 denote the temperatures in degrees Celsius at which the nanoparticles were precipitated from solution.
}

software (Performance in Nanospace, Czech Republic) operating at within 0.2 to $30 \mathrm{kV}$ and $2 \times 10^{-5} \mathrm{~ms}$ to $10 \mathrm{~ms}$ per pixel scanning speed on a $0.5 \mathrm{~g}$ sample, was used to study surface morphology. Fourier Transform Infra-Red Spectroscopy was performed using a PerkinElmer Spectrum Two spectrometer (PerkinElmer Inc., UK) with a 4000 to 400 $\mathrm{cm}^{-1}$ scanning range and $4 \mathrm{~cm}^{-1}$ resolution on a $0.1 \mathrm{~g}$ sample. Brunauer-Emmett-Teller (BET) surface area and porosity analysis were carried out using (i) An ASAP 2020 V4.01 for $\mathrm{CO}_{2}$ adsorptive analysis (Micrometrics, USA) and (ii) A Tristan II 3020 version 2 (Micrometrics, USA) for $\mathrm{N}_{2}$ adsorptive analysis, on $0.4 \mathrm{~g}$ samples.

\section{Photodegradation}

A $10 \mathrm{mg} / \mathrm{L}$ solution was prepared for each dye $(\mathrm{MeO}, \mathrm{MB}$, $\mathrm{RhB}$ ). To $50 \mathrm{~mL}$ of each dye solution, $1.5 \mathrm{~mL}$ of $30 \% \mathrm{H}_{2} \mathrm{O}_{2}$ and $50 \mathrm{mg}$ of $\mathrm{CuO}$ powder were added and the mixture was stirred in the dark for 15 minutes to establish an equilibrium. The mixture was then exposed to a $400 \mathrm{~W}$ white light source, samples were taken at 25 minute intervals for up to 100 minutes and their absorbance recorded to assess the extent and progress of degradation. The suggested mechanism for the degradation for the dye is illustrated in Fig. 1.

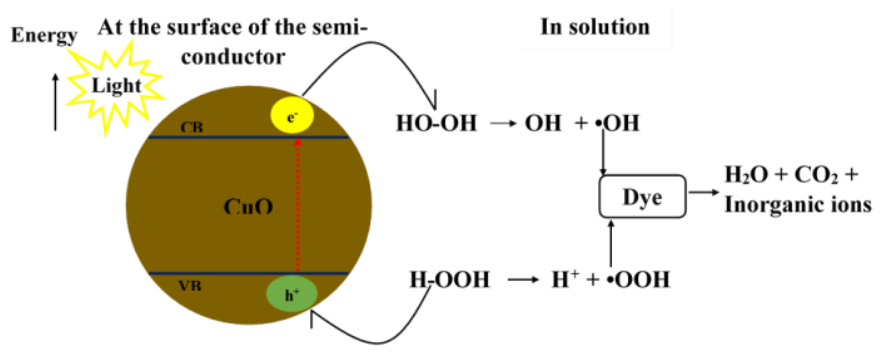

Fig. 1. Simple Representation of the electron-hole pair formation on the surface of $\mathrm{CuO}$ in the presence of $\mathrm{H}_{2} \mathrm{O}_{2}$ and their use in the formation of free radicals for the breakdown of the dye (CB and VB stand for Covalent Band and Valence Band respectively).

\section{RESUlTS AND DISCUSSION}

A summary of the results from characterisation are shown in Table I. The particle sizes were determined using Scherrer's equation and the bandgaps were extrapolated from the Tauc plots for the respective samples. For all three samples after exposure for 100 mins, a minimum of $85 \%$ and a maximum 97 $\%$ degradation were recorded. The degradation summary is shown in Fig. 2 from which it was observed that the photocatalyst generally performed considerably well with the highest percentages recorded for RhB. It was also observed that N60 degraded all dyes by atleast $90 \%$. This could be associated with the fact that it had the highest surface area and largest pore volume (Table I). The degradation arises from the attack of the bonds within the dye by free radicals formed from the attack of the TMO electron on the peroxide molecule in solution (Fig. 1). The amount of dye left was calculated following (4) and (5) and expressed as a percentage of the initial dye concentration. 


$$
\begin{aligned}
& \% \text { Dye left after } t \text { mins }=\left(A_{t} / A_{0}\right) \times 100 \% \\
& \left(A_{0}-A_{t}\right) / A_{0}=\left(C_{0}-C_{t}\right) / C_{0}
\end{aligned}
$$

Where, $\mathrm{A}_{0}=$ Absorbance after 0 minutes of degradation $\mathrm{A}_{\mathrm{t}}=$ Absorbance after $\mathrm{t}$ minutes of degradation $\mathrm{C}_{0}=$ Concentration after 0 minutes of degradation $\mathrm{C}_{\mathrm{t}}=$ Concentration after $\mathrm{t}$ minutes of degradation

The results for each dye over 100 mins are shown in Fig. 3 (a), (b) and (c).

\begin{tabular}{|c|c|c|c|c|c|c|}
\hline Sample Name & $\begin{array}{l}\text { Particle } \\
\text { Size } \\
(\mathrm{nm})\end{array}$ & $\begin{array}{l}\text { Band } \\
\text { Gap } \\
(\mathrm{eV})\end{array}$ & $\begin{array}{l}\text { BET } \\
\text { Surface } \\
\text { Area } \\
\left(\mathrm{m}^{2} / \mathrm{g}\right) \\
\end{array}$ & $\begin{array}{l}\text { Micropore } \\
\text { Surface } \\
\text { Area } \\
\left(\mathrm{m}^{2} / \mathrm{g}\right) \\
\end{array}$ & $\begin{array}{l}\text { Pore } \\
\text { Size } \\
(\mathrm{nm})\end{array}$ & $\begin{array}{l}\text { Pore } \\
\text { Volume } \\
\left(\mathrm{cm}^{3} / \mathrm{g}\right)\end{array}$ \\
\hline S60 & 13.5 & 2.12 & 28.4 & 110.9 & 1.2 & 0.0083 \\
\hline S25 & 13 & 2.11 & 26.8 & 91.7 & 1.3 & 0.0087 \\
\hline N60 & 12 & 2.4 & 49.3 & 206.9 & 0.9 & 0.0105 \\
\hline
\end{tabular}

TABLE I: SUMMARY OF CHARACTERIZATION RESULTS

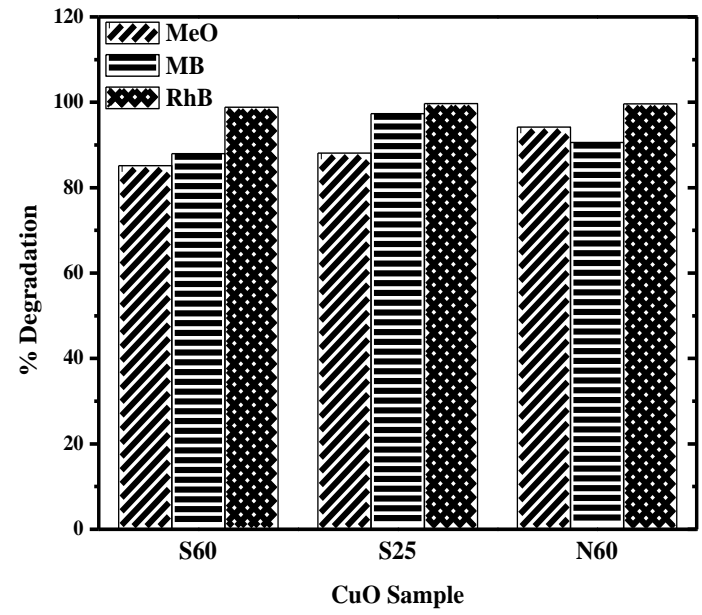

Fig. 2. Summary of degradation results.

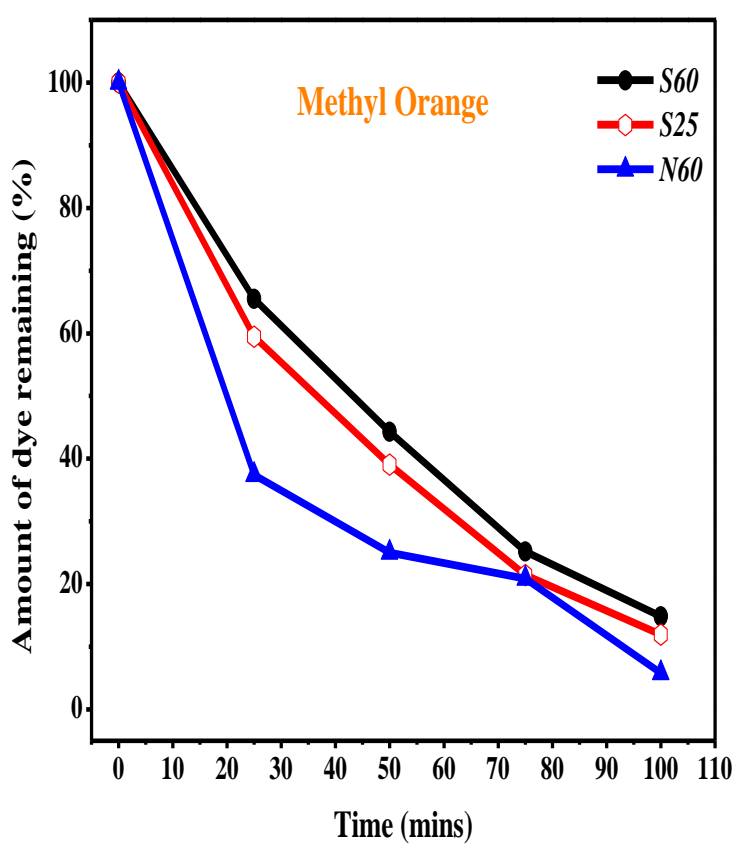

(a)

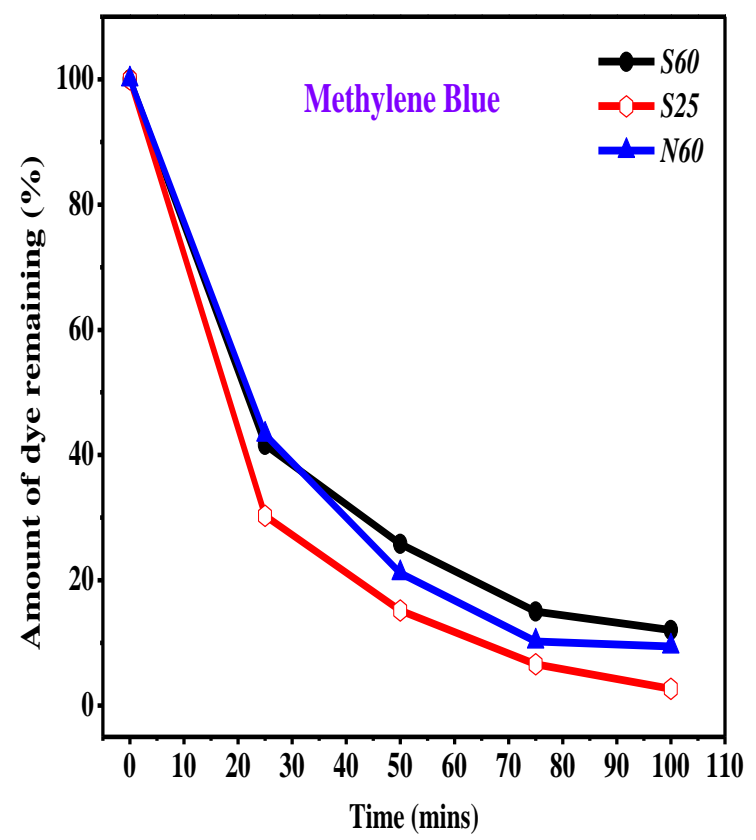

(b) 


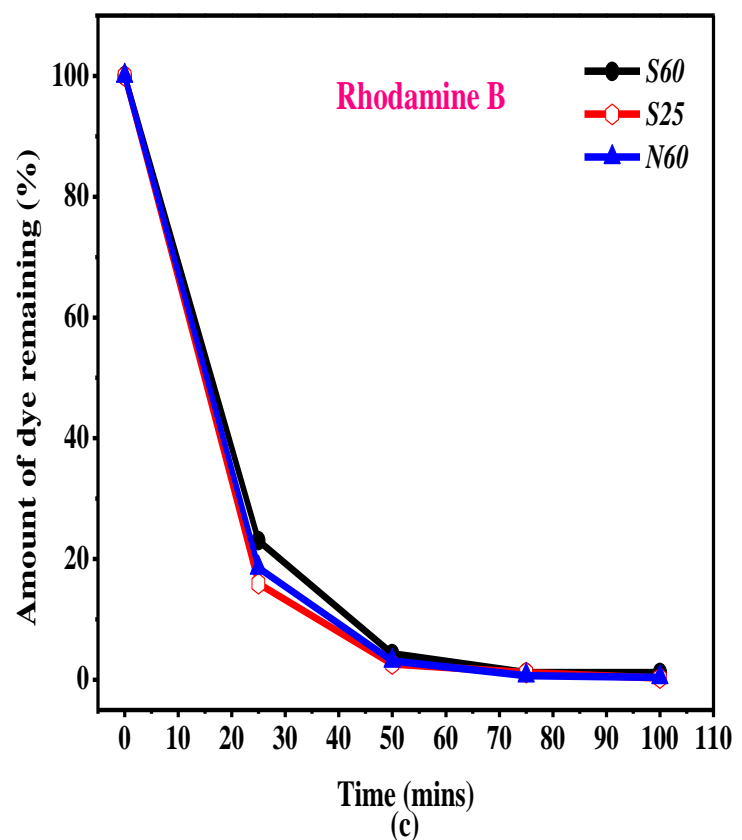

Fig. 3 (a), (b) and (c). Plots showing changes in concentration of the various dyes (expressed as a percentage of the initial amount) with time.

\section{CONCLUSION}

$\mathrm{CuO}$ nanoparticles of different sizes were successfully synthesised from two copper precursor salts using a simple solution method which excludes the use of surfactant. The synthesised nanoparticles were used with success in the photodegradation of $\mathrm{MeO}, \mathrm{MB}$ and $\mathrm{RhB}$ dyes where all three samples performed appreciably well with a minimum of $85 \%$ and maximum of $99 \%$ degradation recorded on average. However, it was observed that though the efficiency for S60 and S25 dropped to below $90 \%$, the degradation efficiency for N60 was consistently equavalent to or higher than $90 \%$ for all three dye solutions. This could be associated with the fact that it showed the highest BET surface area.

However, from the overall result, it is feasible to conclude that the synthesised nanoparticles can be suitable for application in dye photodegradation for wastewater treatment.

\section{REFERENCES}

[1] B. D. C. Ventura-camargo and M. A. Marin-morales, 'Azo Dyes: Characterization and Toxicity - A Review', Text. Light Ind. Sci. Technol. 2(2), vol. 2, no. 2, pp. 85-103, 2013.

[2] A. Majcen-Le Marechal, Y. M. Slokar, and T. Taufer, 'Decoloration of chlorotriazine reactive azo dyes with $\mathrm{H} 2 \mathrm{O} 2 / \mathrm{UV}$ ', Dyes and Pigments, vol. 33, no. 4. pp. 281-298, 1997.

https://doi.org/10.1016/S0143-7208(96)00057-5

[3] P. B. S. Ratna, 'Pollution due to synthetic dyes toxicity \& carcinogenicity studies and remediation', Int. J. Environ. Sci., vol. 3, no. 3, pp. 940-955, 2012.
[4] B. J. Brüschweiler and C. Merlot, 'Azo dyes in clothing textiles can be cleaved into a series of mutagenic aromatic amines which are not regulated yet', Regul. Toxicol. Pharmacol., vol. 88, pp. 214-226, 2017. https://doi.org/10.1016/j.yrtph.2017.06.012

[5] National Center for Biotechnology Information, 'Rhodamine B', PubChem Compound Database; $\mathrm{CID}=6694,2018$. [Online]. Available: https://pubchem.ncbi.nlm.nih.gov/compound/6694. [Accessed: 05-Apr-2018].

[6] K. Kabra, R. Chaudhary, and R. L. Sawhney, 'Treatment of Hazardous Organic and Inorganic Compounds through Aqueous-Phase Photocatalysis: A Review', Ind. Eng. Chem. Res., vol. 43, no. 24, pp. 7683-7696, Nov. 2004. https://doi.org/10.1021/ie0498551

[7] D. Robert and S. Malato, 'Solar photocatalysis: A clean process for water detoxification', Sci. Total Environ., vol. 291, no. 1-3, pp. 85-97, May 2002. https://doi.org/10.1016/S0048-9697(01)01094-4

[8] R. P. Souza et al., 'Photocatalytic activity of $\mathrm{TiO} 2, \mathrm{ZnO}$ and $\mathrm{Nb} 2 \mathrm{O} 5$ applied to degradation of textile wastewater', J. Photochem. Photobiol. A Chem., vol. 329, pp. 9-17, 2016. https://doi.org/10.1016/j.jphotochem.2016.06.013

[9] F. Peng, L. Cai, H. Yu, H. Wang, and J. Yang, 'Synthesis and characterization of substitutional and interstitial nitrogen-doped titanium dioxides with visible light photocatalytic activity', J. Solid State Chem., vol. 181, no. 1, pp. 130-136, 2008. https://doi.org/10.1016/j.jssc.2007.11.012

[10] R. Sasikala, K. Karthikeyan, D. Easwaramoorthy, I. M. Bilal, and S. K. Rani, 'Photocatalytic degradation of trypan blue and methyl orange azo dyes by cerium loaded $\mathrm{CuO}$ nanoparticles', Environ. Nanotechnology, Monit. Manag., vol. 6, pp. 45-53, 2016.

[11] T. H. Tran and V. T. Nguyen, 'Copper Oxide Nanomaterials Prepared by Solution Methods, Some Properties, and Potential Applications: A Brief Review', Int. Sch. Res. Not., 2014.

[12] J. Ma, K. Wang, L. Li, T. Zhang, Y. Kong, and S. Komarneni, 'Visible-light photocatalytic decolorization of Orange II on $\mathrm{Cu} 2 \mathrm{O} / \mathrm{ZnO}$ nanocomposites', Ceram. Int., vol. 41, no. 2, pp. 2050-2056, Mar. 2015. https://doi.org/10.1016/j.ceramint.2014.09.137

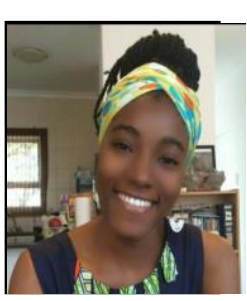

E. Esther Mbu became a member of the Africa Regional International Staff/Student Exchange (ARISE) in 2016, a member of the Bioresource Engineering Research Group (BioERG), Faculty of Applied Science, Department of Biotehnology Cape Peninsula University of Technology in 2018. She holds a Master of Philosophy (MPhil) in Materials Science and Engineering from the University of Ghana, Legon-Accra, Ghana (2018) and a BSc. Chemistry from the University of Buea - Buea Cameroon (2011).

She has a three year working experience in the Oil and Gas Industry where she worked as a Drilling and Measurements Field Specialist in Central and West Africa. 